\title{
A distribution services approach for developing effective competitive strategies against "big box" retailers
}

\author{
Clifford S. Barber, Brian C. Tietje \\ College of Business, California Polytechnic State University, San Luis Obispo, CA 93407, USA
}

\begin{abstract}
According to one theoretical approach, the primary economic function of retailers is to deliver products together with distribution services. We use this framework to identify competitive niches for smaller retailers competing against big box stores. We compare the distribution services offered by the Home Depot versus smaller retailers using both in-store measures and consumer perception data, and the relative importance of distribution services as determinants of store choice. The results show that the Home Depot's superiority in pricing and assortment attracts a significant market, but smaller retailers can secure niche markets by delivering higher levels of ambiance and information.
\end{abstract}

Keywords: Small business; Big box retailing; Competitive advantage

Big box retailers have become a powerful force in retailing today, and their impact on the competitive and economic environment has received considerable attention both in the trade press and academic research. For example, both the Journal of Retailing and Consumer Services (volume 7, issue 4) and the International Journal of Retail \& Distribution Management (volume 28, issue $4 / 5)$ published special issues devoted entirely to the impact of large-format retailers. Smaller retailers who compete against these large firms face tremendous challenges, and several studies provide prescriptive strategies for carving out a competitive niche (Arnold and Luthra, 2000; Brennan and Lundsten, 2000; Darrow et al., 2001; Litz and Stewart, 1998, 2000b, d; Peterson and McGee, 2000). One of the most frequently mentioned competitive advantage opportunities for smaller firms is their provision of personal, value-added services (Andersen, 1997). However, few studies have either measured these services at the retail level, or assessed consumer perceptions of how well retailers deliver them. In this study, we delineate a theoretical framework that defines a broad scope of distribution services, and we use the theory to identify specific types of distribution services that might favor smaller retailers. We then present an empirical study in which we directly measure and assess consumer perceptions of the distribution services provided by the Home Depot, and compare them to the distribution services offered by smaller competitors. We also measure the relative importance of distribution services to consumers in their store patronage. Results from the study indicate that the Home Depot delivers higher levels of several important distribution services, but niche opportunities for smaller retailers are also present.

\section{A distribution services approach to retail strategy}

The theory of distribution services explains that the central economic function of retail firms is "to deliver explicit products or services to consumers together with a variety of distribution services which determine the levels of distribution costs experienced by consumers in their patronage of retailers" (Betancourt and Gautschi, 1988, p. 133). The merchandise and distribution services that are bundled together by retailers serve as outputs of a retailer's production function and fixed inputs in the customer's household production function (Betancourt and Gautschi, 1986, 1988, 1990, 1993). Based on this framework, retail strategy consists of two primary components-merchandise pricing strategy (including 
promotions) and the distribution services that accompany the merchandise.

The distribution services offered by a retailer can be grouped into five general categories: accessibility of location, assortment, assurance of immediate product delivery at the desired time and in the desired form, ambiance, and information (Betancourt and Gautschi, 1988). Each of the distribution services offered by retailers offsets the distribution costs incurred by customers in their purchase and consumption activities. A customer's distribution costs include direct time and transportation, adjustment, psychic, storage, and information. We will briefly define each distribution service and explain how they offset consumers' distribution costs.

Accessibility of location is typically defined as the distance the customer must travel to a retail establishment. Retailers who provide multiple store locations or who locate their stores closer to consumers provide a greater degree of accessibility, and thus reduce the direct time and transportation costs that consumers incur to shop their establishment.

Assortment is defined both by the breadth and depth of a retailer's product mix. When a retailer provides higher levels of assortment, consumers incur less time and transportation costs because they can reduce the number of multiple shopping trips that are necessary to obtain a market basket of goods. Greater assortment also reduces adjustment costs, which are the costs incurred by consumers when they must settle for a product option that does not match their preferences, as they have to delay their purchase and consumption due to product unavailability, or invest more time and effort in multiple shopping trips to locate the product they were seeking.

Higher levels of assurance of immediate product delivery at the desired time and in the desired form are offered when retailers extend their opening hours, offer credit, and break bulk. Assurance is also enhanced when stores reliably keep products in stock and when they make it easy to find products in the store. ${ }^{1}$ These services reduce the direct time costs that consumers incur waiting inside or outside the establishment, adjustment costs due to product unavailability or insufficient resources, and storage costs that result when a product is not available at the desired time in the desired quantities.

Retailers who offer a higher level of ambiance reduce the psychic costs of their patrons, which encompass the hassles of shopping such as drudgery, anxiety or disagreeable social interactions (Betancourt and Gautschi, 1988; Ingene, 1984). The layout of a store, the visual and aesthetic attractiveness of the fixtures and

\footnotetext{
${ }^{1}$ The authors are grateful to an anonymous reviewer for this suggestion.
}

décor, and the friendliness and familiarity of store personnel are formative qualities of ambiance (Bitner, 1992; Eroglu and Machleit, 1990; Kotler, 1973-1974), and enhanced levels of these services reduce consumers' psychic costs.

The final type of distribution service is information, which may include information about prices, availability, product performance, and other elements of the goods and services provided by a retailer. This information can be delivered in two forms: personally via in-store salespeople and impersonally via point-ofpurchase materials. Retailers who offer higher levels of information reduce the costs that customers incur in obtaining the information, as well as adjustment and storage costs that customers incur when information is less accessible.

The competitive model that emerges from the distribution services approach can be described as follows. When retailers offer higher levels of distribution services, they incur higher costs (albeit at varying rates, due to different cost functions). Lower levels of distribution services, meanwhile, lead to higher distribution costs for customers. Customers who patronize a retailer offering lower prices but a less convenient location than another retailer incur greater time and transportation costs in exchange for lower prices. In this case, cost-shifting has occurred - the retailer shifts more distribution costs to the consumer, and in exchange, the consumer pays lower prices for merchandise. Competing retail formats offer distinctive combinations of prices and distribution services, and consumers select the format and retailer whose mix best matches their needs and the costs they are willing to bear. These competing retail formats can co-exist to some extent because they appeal to different segments in the market. However, if one retailer can match the mix of another retailer with lower costs, the inferior firm is unlikely to survive. Smaller retailers face this risk due to the economies of scale afforded to big box retailers (Litz and Stewart, 1998). In the next section, we consider whether these economies of scale are universal across all types of distribution services.

\section{Potential diseconomies of scale in distribution services}

Large-format chain store retailers have presumably achieved economies of scale enabling them to provide a given level of distribution services for a lower cost than smaller competitors (Betancourt and Gautschi, 1986, 1988; see also Darrow et al., 1994; Litz and Stewart, 1998). Furthermore, some of these distribution services benefit from economies of scope, whereby the provision of higher levels of one type of service might lower the marginal costs of providing a given level of a second (Betancourt and Gautschi, 1986). 
Prior research suggests that activities requiring high levels of human labor, personal service, and competence may exhibit diseconomies of scale. In research focusing on potential competitive niches for smaller retailers in the retail hardware industry, Litz and Stewart (1998) suggest that "economies of scale are often outweighed by the diseconomies that come from a loss of human scale and the increase in bureaucracy" (p. 134, see also Bain, 1968). These diseconomies of human scale are particularly relevant for firms engaged in transactions with a high degree of information-intensity (Glazer, 1991), because they are less suitable for large scale transacting (Daft and Lengel, 1990; Litz and Stewart, 1998). Furthermore, retail transactions that have high labor and personal service content would tend to be absent of economies of scale because they are "intrinsically hard to mechanize or routinize" (Porter, 1980, p. 196).

Based on these criteria, the distribution services that may be most prone to diseconomies of scale are information and ambiance. Retailers may have achieved some efficiencies by delivering information using selfservice vehicles such as point-of-purchase displays, but the exchange of more complex and interactive information between a retailer and a customer tends to require considerable personal service. On the other hand, economies of scale might enable larger firms to hire a specialized labor force that is more capable of providing expertise to customers than personnel employed by smaller retailers. Larger retailers may also be able to provide more attractive and user-friendly store fixtures, design, and layout than smaller competitors due to greater resources, but other aspects of ambiance relate to personal services that reduce the drudgery and hassle of shopping, as well as the likelihood of disagreeable social encounters between consumers and retail staff. Larger retailers may have a disadvantage in delivering these distribution services in part because "the inherent scale of the large format creates problems such as unfamiliar staff and an impersonal feeling" (Arnold, 2000, p. iv; see also Morganosky and Cude, 2000).
This study seeks to determine if economies of scale enable a large-format chain store to deliver higher levels of every type of distribution service, or if diseconomies of scale contribute to niche advantages for smaller firms. To address this issue, we measured distribution services at a Home Depot and its smaller competitors using both direct measures and consumer perception data. We also examine the relationship between these measures and consumer store patronage to determine the impact of distribution services on store choice.

\section{Empirical study}

The recent opening of a Home Depot store in a nearby community afforded us the opportunity to track retailer behaviors and customer perceptions and preferences before and after the store opened. The central California community where the store opened has approximately 26,400 residents consisting of 9500 households in a 15-20 square mile area. We chose to focus our study on three stores - the new Home Depot and two incumbent retailers. The first incumbent most closely matches the profile of a neighborhood hardware store. The second incumbent more closely matches the profile of a regional retailer. Table 1 provides a more detailed comparative summary of the retailers who were examined in the study.

These two incumbents were selected for several reasons. First, they represented two different types of retailers that often compete against the Home Depot - smaller neighborhood stores and mid-sized regional stores. Second, their management was willing to share sales and profitability data with us and allow mystery shoppers to visit their stores. They also represented the two primary competitors in the market. There are a few other stores in the city who sell hardware products or building supplies, but they represent a very small share of the overall market, and we were unable to obtain cooperation from the management to participate in the study.

Table 1

Description of the three stores profiled in the study

\begin{tabular}{llll}
\hline & Home Depot & Regional Do-It center & Neighborhood ACE hardware \\
\hline Number of years in business & Just opened & 27 years & 65 years \\
Ownership & National chain & Regionally owned and operated & Locally family owned and operated \\
Size & $105,700 \mathrm{ft}^{2}\left(9820 \mathrm{~m}^{2}\right)$ & $32,500 \mathrm{ft}^{2}\left(3020 \mathrm{~m}^{2}\right)$ & $7500 \mathrm{ft}^{2}\left(697 \mathrm{~m}^{2}\right)$ \\
Number of employees & 150 & 43 & 30 \\
Number of SKUs & 40,000 & 25,000 & 12,000 \\
$\begin{array}{l}\text { Distance from center of } \\
\text { town }\end{array}$ & 4 miles $(6.4 \mathrm{~km})$ & 1.5 miles $(2.4 \mathrm{~km})$ & $1.2 \mathrm{miles}(1.9 \mathrm{~km})$ \\
Comments & & Underwent a major renovation & Largest lumberyard of the three stores \\
& & during a portion of the study period & \\
\hline
\end{tabular}




\subsection{Consumer survey}

In order to track consumer preferences and perceptions of distribution services in the local retail hardware industry before and after the Home Depot store opened, two waves of consumer survey data were collected. The first wave of data was collected 2 months before the Home Depot store opened. Five thousand surveys were distributed through the mail to a random sample of local households. The addresses were purchased from a local mailing service. Of the mailed surveys, 1000 were returned due to incorrect addresses, vacancies, or other postal hindrances. Of the remaining surveys, 800 were returned in completed form $(20 \%$ response rate among the surveys that reached their intended address). Due to budget constraints, only 2000 surveys were distributed during the second round of data collection, which occurred 6 months after the Home Depot store had opened. Once again, a random sample of household addresses was purchased. Of the mailed surveys, 450 were returned due to an incorrect address or residential vacancy. 330 surveys were returned in completed form ( $21 \%$ response rate).

The survey instrument that was used during both data-collection periods was identical, with one exception. The first survey referred to the closest Home Depot store at that time, which was 45 miles from the town. The second survey referred to the new Home Depot store that opened locally. Otherwise, all of the measures were identical so that the data from the two waves could be compared.

The primary purpose of the survey was to measure the importance of each of the various distribution services to consumers in their store patronage, and to measure consumer perceptions of the relative level of these distribution services at each of the stores in question. The survey had six sections. The first question was for screening purposes, and asked if the respondent had purchased hardware or home improvement products at a retail store in the last year, either for personal or commercial use. The second question asked how frequently the respondent purchased hardware/home improvement products. Choices ranged from less than once per month to more than once per week. The third question asked which store the respondent shopped at most frequently. Respondents were instructed to check only one of the boxes corresponding to one of 12 stores in the area, or they could check an "other" box and write in their own store choice.

In section four, respondents were asked to select the single most important reason that determined which retail hardware store they shopped at most often. They could select from a list of 20 items, or they could select "other" and write in their own choice. The 20 items were developed to provide multiple indicators of pricing and each of the five distribution services. Several of these questions were similar to those used in prior research that examined the impact of large-format stores on consumer preferences (Arnold et al., 1998).

In section five, respondents were asked to rate the importance of each of the 20 aforementioned items on a scale of $1=$ little importance to $5=$ extreme importance. In the final section, respondents were instructed to indicate which of the competing stores performed best on each item.

The 20 scale items used in the consumer survey were analyzed using principal components and reliability analysis for scale reduction. Fourteen of the items matched the six factors that were of focal interest in this study — pricing and the five distribution services, and six items were dropped due to low item-to-total correlations and factor loadings (see Table 2).

While the consumer survey measured perceptions of distribution services and their importance, direct measures of distribution services using mystery shoppers were also obtained to provide an additional point of reference.

\subsection{In-store measures of distribution services}

Individuals who were not directly involved in the study were recruited as mystery shoppers to collect the in-store data. The six mystery shoppers included a mix of males and females and ranged in age from 20 to 38 years old. The shoppers were randomly assigned to each of the stores in an effort to minimize potential biases due to age, sex, personality, or other individual differences. The shoppers were provided with surveys and verbal and written instructions for each step of the datacollection process. Prior authorization was obtained from each of the stores to allow for the data collection to take place. Every effort was made to disguise the identity of each mystery shopper, to prevent any differences in behaviors or service levels by the store personnel when the shopper was present. Furthermore, store personnel did not know what specific measures the shopper was gathering. In-store data for the two incumbent retailers are based on 11 observations - four prior to the opening of the Home Depot, four taken 3 months after the Home Depot opened, and three taken 6 months after the Home Depot opened. In-store data for the Home Depot are based on seven observations - four taken 1 month after the store opened, and three taken 6 months after the store opened.

Proxy measures of pricing and each of the five categories of distribution services were obtained. In order to compare pricing and assortment across the stores over time, the creation of a market basket of items that is representative of the typical assortment within a retail hardware store was necessary. A pricing analyst from a national trade name franchise provided assistance in developing a market basket of 24 products that 
Table 2

Survey items used to measure consumer perceptions of distribution services

\begin{tabular}{|c|c|c|c|c|c|}
\hline \multirow[t]{2}{*}{ Strategic component } & \multirow[t]{2}{*}{ Scale item } & \multicolumn{2}{|c|}{ Item-total correlation } & \multicolumn{2}{|l|}{ Alpha } \\
\hline & & Wave I & Wave II & Wave I & Wave II \\
\hline Price & $\begin{array}{l}\text { Everyday prices } \\
\text { Sale prices }\end{array}$ & 0.547 & 0.408 & 0.700 & 0.571 \\
\hline \multirow{3}{*}{ Assortment } & Overall product selection & 0.652 & 0.576 & 0.833 & 0.825 \\
\hline & Number of different product categories offered & 0.744 & 0.779 & & \\
\hline & Range of selection within each product category & 0.701 & 0.717 & & \\
\hline \multirow[t]{3}{*}{ Ambiance } & Store layout & 0.664 & 0.619 & 0.806 & 0.766 \\
\hline & Store atmosphere & 0.670 & 0.676 & & \\
\hline & Speedy checkouts & 0.499 & 0.511 & & \\
\hline \multirow[t]{2}{*}{ Assurance } & Has merchandise in stock & 0.493 & 0.551 & 0.655 & 0.702 \\
\hline & Quality of merchandise & & & & \\
\hline \multirow[t]{3}{*}{ Information } & Overall service level & 0.662 & 0.619 & 0.814 & 0.794 \\
\hline & Knowledgeable employees & 0.701 & 0.700 & & \\
\hline & Friendly employees & 0.647 & 0.598 & & \\
\hline Accessibility & Store location and convenience & & & & \\
\hline \multirow[t]{6}{*}{ Items selected for removal } & Home delivery & & & & \\
\hline & Store hours & & & & \\
\hline & Ease of returns and exchanges & & & & \\
\hline & Familiar employees & & & & \\
\hline & Product information in the store & & & & \\
\hline & Product information on the Web & & & & \\
\hline
\end{tabular}

included items defined as either price-sensitive, competitive, non-competitive, or blind, within each of the major product lines in the retail hardware industry (see Table 3).

Price-sensitive items are considered highly recognizable with high household penetration, are frequently promoted, and have prices that customers would be familiar with, at least within a suitable range. Competitive items are high velocity and are identical to what the competition is likely to have in its own assortment. Customers would also be likely to have a narrow price expectation range for competitive items. Non-competitive and blind items tend to have low price recognition, are not likely to be competitively shopped, are not easily compared by the customer, are typically lower ticket items and include items such as repair and replacement products, status or luxury items, or items requiring extra service time (e.g., cutting keys) as a necessity and not as a value-added service.

Product assortment was measured by tracking the number of items within the market basket that the store carried, based on the presence or absence of a shelf tag for the item and/or the availability of the item itself. Ambiance was measured with a six-item store atmosphere rating, in which the mystery shoppers responded to statements such as "the store has a pleasant atmosphere" on a 7-point scale ranging from "strongly disagree" to "strongly agree". Four of these items were borrowed from the store image scale developed by $\mathrm{Wu}$ and Petroshius (1987), and the other two items referred to the store being crowded and loud. Accessibility was measured by the total number of hours the store was open each week.

Two proxy measures of assurance of immediate product delivery at the desired time and in the desired form were obtained. First, shelf inventories were checked to determine how many of the 24 items in the market basket were in stock at the time of the observation. Second, mystery shoppers measured how much time was required to purchase a single item. The stopwatch started when the shopper got out of his/her car in the parking lot, and stopped when the shopper returned to the car. Thus, this measure incorporates the time required to enter the store, locate the product, purchase the product, and return to the car. The item chosen for purchase was the same for all stores during each observation period. During the first week of the in-store measures, for example, the shoppers purchased two half-inch flat washers in each of the stores. Items were chosen to represent a broad crosssection of products available in a retail hardware store, and some were selected on the basis that they would require a greater degree of assistance from store personnel. 
Table 3

Market basket of items used in study

\begin{tabular}{|c|c|c|}
\hline Department & Market basket item & Pricing category \\
\hline Paint & $\begin{array}{l}\text { SprayKrylon Gloss White } \\
3 \mathrm{M} \frac{3}{4} \text { in } \times 60 \mathrm{ft} \text { Masking Tape } \\
2 \text { in foam paintbrush } \\
\text { Mop \& Bucket Wringer ( } 35 \\
\text { quart) }\end{array}$ & $\begin{array}{l}\text { Price sensitive } \\
\text { Competitive } \\
\text { Blind } \\
\text { Non-competitive }\end{array}$ \\
\hline Tools & $\begin{array}{l}1 \text { in } \times 25 \mathrm{ft} \text { Stanley } \\
\text { Measuring Tape }^{\mathrm{a}} \\
3 \mathrm{M} \text { Dust Mask } \\
\left.\frac{1}{4} \text { in t-50 staples ( } 1250 \text { count }\right) \\
3 / 8 \text { in Drill Bit ( } 4 \text { in long) }\end{array}$ & $\begin{array}{l}\text { Price sensitive } \\
\text { Competitive } \\
\text { Non-comparable } \\
\text { Blind }\end{array}$ \\
\hline Electrical & $\begin{array}{l}\text { Single toggle switch wall } \\
\text { plate (white) } \\
100 \mathrm{ft} \text { Ext Cord } 16 / 3^{\mathrm{a}} \\
3 \text { Way Bulb } 50 / 150 \mathrm{~W}^{\mathrm{a}} \\
\text { Ceiling fan w/Light }\end{array}$ & $\begin{array}{l}\text { Price sensitive } \\
\text { Price sensitive } \\
\text { Non-competitive } \\
\text { Competitive }\end{array}$ \\
\hline Plumbing & $\begin{array}{l}\text { Liquid Plumber quart } \\
\text { Duck Tape } 2 \text { in } \times 60 \mathrm{ft}^{\text {a }} \\
\frac{1}{2} \text { in } \times 10 \mathrm{ft} \mathrm{copper} \mathrm{tubing} \\
(\text { Type M) } \\
\text { White toilet seat }^{\mathrm{a}}\end{array}$ & $\begin{array}{l}\text { Price sensitive } \\
\text { Competitive } \\
\text { Price sensitive } \\
\text { Price sensitive }\end{array}$ \\
\hline Hardware & $\begin{array}{l}\text { First Alert Smoke Detector }^{\mathrm{a}} \\
\text { Quikrete } 60 \mathrm{lb} . \mathrm{Bag} \\
\frac{1}{4} \text { in Flat Washer } \\
\text { Entry Lock with deadbolt }^{\mathrm{a}}\end{array}$ & $\begin{array}{l}\text { Price sensitive } \\
\text { Price sensitive } \\
\text { Blind } \\
\text { Competitive }\end{array}$ \\
\hline $\begin{array}{l}\text { Lawn and } \\
\text { Garden }\end{array}$ & $\begin{array}{l}\text { Roundup Gallon } \\
5 / 8 \text { in } \times 60 \mathrm{ft} \text { Rubber Hose } \\
\text { Victor mousetrap } 2 \text { pk } \\
\text { Gas String Trimmer } 17 \text { in }\end{array}$ & $\begin{array}{l}\text { Price sensitive } \\
\text { Competitive } \\
\text { Blind } \\
\text { Competitive }\end{array}$ \\
\hline
\end{tabular}

Totals: price sensitive (10), competitive (7), blind (4), non-competitive (3).

${ }^{\text {a }}$ Indicates item used to calculate share-weighted price index.

Information services were measured by having the mystery shoppers observe if any of the four types of information were available in the store: (1) "how to" or instructional flyers, (2) specific product information, (3) in-store training, and (4) any other types of information that could assist a customer in the process of choosing and using a product or solving a problem. The highest score possible was a four, indicating the presence of all four types of information.

As detailed by Finn and Kayande (1999) mystery shopper data can provide useful information for judging both the objective and subjective characteristics of retailer performance. However, some limitations should be noted. Inter-item reliability for the mystery shopper data could not be calculated because the shoppers did not use a coding scheme with nominal data (i.e., classifying a store into categories). The shoppers were gathering interval and ratio data, such as the time required to purchase an item. However, because we
Table 4

Summary of "mystery shopper" in-store measures of distribution services

\begin{tabular}{|c|c|c|c|c|}
\hline & Pre-HD & Wave II & Wave III & Avg. \\
\hline \multicolumn{5}{|c|}{ Part $A$-share-weighted price index } \\
\hline Home Depot & & 150.0 & 147.9 & 148.9 \\
\hline Do-It & 213.6 & 192.4 & 230.3 & 212.1 \\
\hline ACE & 155.6 & 180.7 & 189.9 & 175.4 \\
\hline \multicolumn{5}{|c|}{ Part B_\% of market basket carried by store } \\
\hline Home Depot & & $100.0 \%$ & $92.0 \%$ & $96.0 \%$ \\
\hline Do-It & $89.0 \%$ & $75.3 \%$ & $87.7 \%$ & $84.0 \%$ \\
\hline ACE & $100.0 \%$ & $90.0 \%$ & $92.0 \%$ & $94.0 \%$ \\
\hline \multicolumn{5}{|c|}{ Part $C$-store atmosphere rating } \\
\hline Home Depot & & 4.67 & 5.11 & 4.9 \\
\hline Do-It & 3.88 & 4.38 & 5.78 & 4.7 \\
\hline $\mathrm{ACE}$ & 6.13 & 5.42 & 5.89 & 5.8 \\
\hline \multicolumn{5}{|c|}{ Part D_\% of market basket in stock } \\
\hline Home Depot & & $100.0 \%$ & $92.0 \%$ & $96.0 \%$ \\
\hline Do-It & $90.0 \%$ & $74.0 \%$ & $87.7 \%$ & $83.9 \%$ \\
\hline ACE & $98.0 \%$ & $80.0 \%$ & $92.0 \%$ & $90.0 \%$ \\
\hline \multicolumn{5}{|c|}{ Part E-total weekly store hours } \\
\hline Home Depot & & 107 & 107 & 107 \\
\hline Do-It & 76 & 71 & 78 & 75 \\
\hline ACE & 74 & 69 & 73 & 72 \\
\hline \multicolumn{5}{|c|}{ Part $F$-time required to purchase an item $(s)$} \\
\hline Home Depot & & 675 & 307 & 491 \\
\hline Do-It & 255 & 249 & 230 & 245 \\
\hline ACE & 261 & 358 & 148 & 256 \\
\hline \multicolumn{5}{|c|}{ Part $G$-In-store product information } \\
\hline Home Depot & & 3.50 & 2.33 & 2.9 \\
\hline Do-It & 1.25 & 1.50 & 0.67 & 1.1 \\
\hline $\mathrm{ACE}$ & 0.75 & 1.00 & 1.00 & 0.9 \\
\hline \multicolumn{5}{|c|}{ Part $H$-time required to obtain assistance $(s)$} \\
\hline Home Depot & & 2295 & 278 & 1287 \\
\hline Do-It & 644 & 335 & 826 & 602 \\
\hline ACE & 243 & 572 & 125 & 313 \\
\hline
\end{tabular}

report averages in Table 4 that include as many as 11 observations per store, these data do incorporate a greater degree of reliability than a single observation. We feel that the mystery shopper data provide a useful compliment to the consumer survey data, and illustrate several methods that can be used to compare distribution service levels across retailers.

\subsection{Results: comparing distribution services across retailers}

The in-store data captured by mystery shoppers and the consumer data provide relative measures of the pricing and distribution services offered by the competing retailers. 
Table 5

Proportion of total respondents who selected each retailer as the best performer

\begin{tabular}{|c|c|c|c|c|c|c|c|c|c|}
\hline \multirow[b]{3}{*}{ Wave of survey } & \multicolumn{9}{|c|}{ Best performer } \\
\hline & \multicolumn{3}{|c|}{ Home Depot } & \multicolumn{3}{|c|}{ Do-It } & \multicolumn{3}{|l|}{ ACE } \\
\hline & I & II & TTL & I & II & TTL & I & II & TTL \\
\hline \multicolumn{10}{|l|}{ Performance variable } \\
\hline Everyday prices & 60.1 & 70.2 & 62.9 & 28.3 & 19.4 & 25.8 & 8.5 & 8.7 & 8.5 \\
\hline Sale prices & 54.1 & 60.1 & 55.8 & 30.2 & 29.4 & 30.0 & 9.7 & 9.2 & 9.6 \\
\hline Pricing & 57.2 & 65.3 & 59.5 & 29.2 & 24.3 & 27.8 & 9.1 & 9.0 & 9.0 \\
\hline Overall product selection & 59.8 & 75.8 & 64.3 & 29.7 & 19.7 & 26.9 & 9.8 & 4.2 & 8.2 \\
\hline Number of different product categories offered & 62.1 & 81.2 & 67.4 & 28.2 & 14.5 & 24.4 & 8.4 & 3.6 & 7.1 \\
\hline Range of selection within each product category & 59.8 & 76.2 & 64.4 & 29.2 & 18.2 & 26.2 & 9.2 & 5.3 & 8.1 \\
\hline Assortment & 60.5 & 77.7 & 65.3 & 29.1 & 17.5 & 25.8 & 9.1 & 4.4 & 7.8 \\
\hline Store layout & 34.4 & 37.9 & 35.3 & 47.6 & 52.0 & 48.8 & 13.8 & 9.1 & 12.5 \\
\hline Store atmosphere & 18.9 & 24.4 & 20.4 & 52.1 & 57.1 & 53.5 & 20.2 & 16.5 & 19.1 \\
\hline Speedy checkouts & 19.7 & 23.8 & 20.9 & 44.0 & 50.7 & 45.9 & 21.9 & 21.9 & 21.9 \\
\hline Ambiance & 24.4 & 28.7 & 25.6 & 47.9 & 53.3 & 49.4 & 18.6 & 15.8 & 17.8 \\
\hline Store location and convenience (Accessibility) & 6.2 & 29.3 & 12.5 & 58.3 & 53.0 & 56.9 & 18.1 & 14.3 & 17.1 \\
\hline Has merchandise in stock & 47.3 & 64.5 & 52.1 & 37.6 & 25.0 & 34.1 & 12.5 & 10.5 & 12.0 \\
\hline Quality of merchandise & 34.0 & 46.0 & 37.3 & 42.0 & 36.3 & 40.5 & 20.4 & 17.0 & 19.5 \\
\hline Assurance & 40.7 & 55.4 & 44.8 & 39.8 & 30.6 & 37.3 & 16.5 & 13.7 & 15.7 \\
\hline Overall service level & 19.9 & 27.8 & 22.1 & 51.2 & 45.2 & 49.5 & 23.2 & 25.4 & 23.8 \\
\hline Knowledgeable employees & 19.0 & 26.5 & 21.1 & 48.5 & 41.7 & 46.6 & 27.2 & 29.8 & 27.9 \\
\hline Friendly employees & 14.3 & 25.3 & 17.4 & 51.6 & 46.9 & 50.3 & 23.5 & 24.7 & 23.8 \\
\hline Information & 17.8 & 26.5 & 20.2 & 50.4 & 44.6 & 48.8 & 24.7 & 26.7 & 25.2 \\
\hline
\end{tabular}

\subsubsection{Pricing}

In order to compare pricing between the stores, a share-weighted price index was calculated using 10 items in the market basket for which comparable prices were available for all three stores across all time periods. Prices for each of these 10 items were multiplied by a weighting factor to create a single item index. The weighting factor for each item was obtained by multiplying the percentage of total retail dollar sales the item generated times the percentage of total retail dollar sales generated by the category the item was in. (These data were obtained from a pricing analyst at one of the national hardware cooperatives.) For example, a 2-in foam paintbrush delivered $1.66 \%$ of total retail dollar sales at the cooperative, and the paint department delivered $14 \%$ of the dollar sales relative to the overall store. Thus, the weighting for this product was $0.0166 \times 0.14=0.002324$. This weighting was multiplied times the actual price of the product in each store to generate a single-item price index. The process was repeated for each of the 10 items, and the total pricing index for each store was the sum of these 10 indices.

The Home Depot had a lower share-weighted price index during both time periods following its opening. The neighborhood ACE store had the second-lowest prices, and the regional Do-It center had the highest prices among the three stores (see Table 4, part A).

Consumer perceptions of pricing among the retailers also favored the Home Depot before and after the new store opened. When asked to indicate which retailer performed best on everyday and sale prices, a majority of respondents selected Home Depot (see Table 5).

These results confirm that consumers perceive Home Depot to have superior pricing, and the price index data suggest that these perceptions are accurate.

\subsubsection{Assortment}

Home Depot carried the highest percentage of the 24 items in the market basket (see Table 4, part B), followed closely by the neighborhood ACE store. The Do-It center had the lowest assortment among the market basket. Another measure of assortment is the total number of SKUs carried by each store. Self-report data from store personnel and business publications indicate that the average Home Depot has about 40,000 SKUs, the regional Do-It center has 25,000, and the neighborhood ACE store has about 12,000. On the basis of both measures, Home Depot carries the largest assortment. Whether the Do-It center or the ACE store has a greater assortment depends on the measures used. Another factor that is not accounted for in our measures 
is that the ACE store has the most extensive lumberyard of any of the three stores, but lumber items are not included in the market basket.

Consumer perceptions of assortment weighed heavily in favor of the Home Depot, even before the store opened locally (see Table 5). During both waves of consumer surveys, most respondents felt that the Home Depot had the best overall product selection, the largest number of different product categories, and the broadest range of selection within each product category (the three survey items that were combined to generate the assortment measure).

\subsubsection{Ambiance}

The neighborhood ACE store received the highest store atmosphere ratings by the mystery shoppers across all three stages of in-store data collection (see Table 4, part C). One complicating factor is that the Do-It store underwent a major renovation during a 6-month period that began shortly before the Home Depot opened. Following the completion of the Do-It center renovation, the ACE store still maintained the highest ratings, followed by the Do-It center and the Home Depot.

Consumer perceptions of store layout, store atmosphere, and speedy checkouts - the three survey measures that related to store ambiance-favored the Do-It center. The impact of the Do-It center's store renovation is evidenced by the increase in the proportion of respondents who favored their ambiance during the second wave of data collection.

\subsubsection{Accessibility}

Accessibility is typically defined and measured in the distribution services literature as the physical distance that consumers must travel to the retail establishment. For purposes of our study, we measured accessibility by the number of miles from the center of town to each store, and the store's proximity to population densities. The Do-It center and the neighborhood ACE store are both located on the town's major thoroughfare and are 1.5 and 1.2 miles south of the town center, respectively. The Home Depot store is on the northern edge of the city limits, 4 miles north of the town center, and is located near an exit from a major highway that runs parallel to the city's thoroughfare. Both incumbent retailers are within a region that is zoned for denser housing populations (e.g., multi-family housing units), compared to the locale of the Home Depot, which is zoned primarily for rural and single family residential.

Consumer perceptions of accessibility were measured in the survey with a question relating to the store's "location and convenience", with an explanation in parentheses stating "easy to get to from your home or place of business". Despite the fact that the Do-It center and ACE store were only three-tenths of a mile from each other on the same thoroughfare, a larger percen- tage of respondents felt that the Do-It center was the best performer on store location and convenience than either the ACE store or the Home Depot (see Table 5). The fact that a majority of respondents during both waves of data collection voted the Do-It center as having the best location and convenience suggests that travel distance may not be the only factor to consider when accessibility is measured. For example, the Do-It center has a larger parking lot than the ACE store. In addition, the Do-It center is part of a two-store chain, and the other store is located in a larger city 20 miles from the location used in the study. These factors, among others, may have impacted consumer perceptions of location and convenience.

\subsubsection{Assurance of product delivery at the desired time and in the desired form}

We used three in-store measures to capture the level of assurance of product delivery at the desired time and in the desired form - the percentage of the market basket that was in stock during each observation, the total number of hours each store was open during the study period, and the time required to purchase an item. The in-stock data closely matched the overall distribution data. The Home Depot had the highest percentage of the market basket items in stock, followed by the ACE store, and the Do-It center had the lowest (see Table 4, part D). The Home Depot offered the most extensive store hours, over 30 hours per week more than either of the two incumbents (see Table 4, part E). Both of these measures favor Home Depot. However, the average time required to purchase an item was in direct correlation with the size of the retailer (see Table 4, part F). The neighborhood ACE store tended to deliver faster transaction speed than the other two stores.

The two consumer survey items relating to assurance-has merchandise in stock and the quality of the merchandise - favored the Home Depot, followed by the Do-It center and the ACE store. However, the percentage of respondents who felt that the Home Depot was best in having merchandise in stock was higher than those who felt the Home Depot had the best quality of merchandise (see Table 5).

\subsubsection{Information services}

The Home Depot provided more in-store product information than either of the two incumbent retailers (Table 4, part G), but less time was required to receive unsolicited assistance in the neighborhood ACE store than the Do-It center or the Home Depot. These two measures contrast information services that are available for customers who seek self-service information versus personal service.

More consumers felt that the Do-It center performed best on factors relating to information services than 
either of the other two retailers during both waves of data collection (see Table 5). However, the percentage of respondents who chose the Do-It center as the best performer dropped from wave I to wave II. The Home Depot had increases in every element relating to information services from wave I to wave II. The ACE store managed increases in perceptions of its overall service level and knowledgeable employees. Despite having a lower market share than the Home Depot, the ACE store still received more first-place votes for knowledgeable employees than the Home Depot in wave II.

An interesting contrast is between perceptions of best performance on personal service relative to self-service sources of information. The incumbents were stronger on the former, while the Home Depot scored better on the latter.

\subsection{Discussion: comparing distribution services across retailers}

Some of the results from both the in-store measures and the consumer survey confirm what most observers would already believe - that the Home Depot is known for and provides superior pricing and assortment. The results also reveal four primary opportunities for incumbent retailers. First, both in-store measures and consumer perceptions of ambiance were rated in favor of the incumbents. Second, both of the incumbents provide higher levels of accessibility, both in terms of the actual distance of their stores from the city-center and consumer perceptions of store location and convenience. Third, the incumbents maintained an advantage in speed, which relates to assurance of product delivery at the desired time. The average time required to purchase an item and consumer perceptions of speedy checkouts favored the incumbents. Finally, the incumbents exhibited an advantage in providing personal services. In-store measures of the time required to obtain unsolicited assistance and consumer perceptions of the stores' overall service levels and knowledgeable employees were higher for the incumbents than Home Depot. This suggests that the "three legged stool" analogy of Home Depot's superiority in assortment, price, and service (Darrow et al., 1994; Marcus et al., 1999) may not hold true in all instances.

Given these potential niche opportunities for small retailers, the question is whether they are important enough to a sufficiently large share of the market to provide a base of business for the incumbent retailers. In the next set of analysis, consumer ratings of the importance of the various distribution services are analyzed to identify potential market segments who prefer the mix of distribution services offered by the incumbent retailers.

\subsection{Results and discussion: importance ratings of distribution services}

Prior research suggests that in some cases a "market spoiler", or a new large-format retailer, can actually change customer preferences by capitalizing on the ambiguity of those preferences (Arnold et al., 1998). In contrast to the hypothesis implied by the aforementioned research, consumer preferences remained remarkably consistent between the two waves of data collection (see Table 6).

None of the $t$-tests comparing the average importance ratings of each of the distribution services or pricing were significant at the 0.05 level. These results indicate either that the Home Depot's entry into the market did not change consumer preferences, or that not enough time had elapsed to allow for such changes to occur.

The consumer survey data and in-store measures of retailer performance suggested that the incumbent retailers had four potential advantages - ambiance (reducing consumers' psychic costs), accessibility (reducing consumers' time and travel costs), assurance of product delivery at the desired time (reducing consumers' time costs) and information (reducing consumers' own costs of obtaining information). The factor importance ratings for shoppers most loyal to each of the retailers are consistent with these opportunities (see Table 7).

Consumers who most often shop at the Home Depot place greater importance on pricing and assortment than consumers who shop at the regional Do-It store ( $t=4.07, p<0.001$ for pricing; and $t=5.84, p<0.001$ for assortment) and the neighborhood ACE store ( $t=4.24, p<0.001$ for pricing; and $t=4.95, p<0.001$ for assortment). Furthermore, Home Depot shoppers place less importance on accessibility than consumers who shop at the regional Do-It store $(t=2.62$, $p=0.009$ ). Shoppers most loyal to the neighborhood ACE store place greater importance on information than the Do-It center shoppers $(t=2.59, p=0.01)$, and the Home Depot patrons $(t=4.39, p<0.001)$.

Table 6

Average importance ratings before and after Home Depot opened

\begin{tabular}{llll}
\hline Factor & $\begin{array}{l}\text { Importance } \\
\text { rating wave I } \\
\text { (Before HD } \\
\text { opened) } \\
n=871\end{array}$ & $\begin{array}{l}\text { Importance } \\
\text { rating wave II }\end{array}$ & $\begin{array}{l}\text { Combined } \\
\text { importance } \\
\text { rating }\end{array}$ \\
\hline Assurance & 4.41 & 4.38 & \\
Information & 4.16 & 4.19 & 4.40 \\
Assortment & 4.01 & 4.01 & 4.17 \\
Accessibility & 4.01 & 4.01 & 4.01 \\
Price & 3.76 & 3.78 & 3.76 \\
Ambiance & 3.16 & 3.27 & 3.19 \\
\hline
\end{tabular}


Table 7

Average importance ratings for shoppers most loyal to each retailer

\begin{tabular}{|c|c|c|c|c|c|c|c|c|c|}
\hline \multirow[b]{3}{*}{ Wave of survey } & \multicolumn{9}{|c|}{ Where shop most often } \\
\hline & \multicolumn{3}{|c|}{ Home Depot } & \multicolumn{3}{|l|}{ Do-It } & \multicolumn{3}{|l|}{$\mathrm{ACE}$} \\
\hline & I & II & $\mathrm{TTL}^{\mathrm{a}}$ & I & II & TTL & I & II & TTL \\
\hline \# Of respondents & 32 & 114 & 146 & 553 & 124 & 677 & 137 & 27 & 164 \\
\hline \multicolumn{10}{|l|}{ Factor importance } \\
\hline Pricing & 4.05 & 4.09 & $4.08 \mathrm{a}$ & 3.78 & 3.57 & $3.74 b$ & 3.71 & 3.50 & $3.68 b$ \\
\hline Assortment & 4.55 & 4.33 & $4.38 \mathrm{a}$ & 4.04 & 3.84 & $4.00 \mathrm{~b}$ & 3.99 & 3.99 & $4.00 \mathrm{~b}$ \\
\hline Ambiance & 3.02 & 3.12 & 3.09 & 3.15 & 3.33 & 3.18 & 3.21 & 3.60 & 3.27 \\
\hline Accessibility & 3.72 & 3.89 & $3.86 \mathrm{a}$ & 4.06 & 4.16 & $4.08 b$ & 4.01 & 4.19 & $4.04 \mathrm{a}, \mathrm{b}$ \\
\hline Assurance & 4.61 & 4.52 & $4.54 \mathrm{a}$ & 4.42 & 4.33 & $4.40 \mathrm{~b}$ & 4.43 & 4.29 & $4.41 \mathrm{~b}$ \\
\hline Information & 4.09 & 3.97 & $4.00 \mathrm{a}$ & 4.14 & 4.22 & $4.15 b$ & 4.28 & 4.51 & $4.31 \mathrm{c}$ \\
\hline
\end{tabular}

${ }^{\mathrm{a}}$ Values with equivalent subscripts are statistically equivalent.

Table 8

Proportion of respondents selecting each factor as the primary determinant of store choice for shoppers most loyal to each retailer

\begin{tabular}{|c|c|c|c|c|c|c|c|c|c|c|}
\hline \multirow[b]{3}{*}{ Wave of survey } & \multicolumn{9}{|c|}{ Where shop most often } & \multirow[b]{3}{*}{ Total sample } \\
\hline & \multicolumn{3}{|c|}{ Home Depot } & \multicolumn{3}{|l|}{ Do-It } & \multicolumn{3}{|l|}{$\mathrm{ACE}$} & \\
\hline & I & II & TTL & I & II & TTL & I & II & TTL & \\
\hline \# Of respondents & 31 & 113 & 144 & 549 & 121 & 670 & 132 & 22 & 154 & \\
\hline$\%$ Of respondents & 3.6 & 40.5 & 12.7 & 64.3 & 43.4 & 59.1 & 15.5 & 7.9 & 13.6 & \\
\hline \multicolumn{11}{|c|}{ Most important factor } \\
\hline Pricing & 35.5 & 32.7 & 33.3 & 10.4 & 6.6 & 9.7 & 12.9 & 0 & 11.0 & 14.1 \\
\hline Assortment & 54.8 & 47.8 & 49.3 & 30.6 & 17.4 & 28.2 & 21.2 & 13.6 & 20.1 & 27.8 \\
\hline Ambiance & 0 & 0 & 0 & 1.3 & 2.5 & 1.5 & 1.5 & 0 & 1.3 & 1.3 \\
\hline Accessibility & 0 & 11.5 & 9.0 & 35.0 & 48.8 & 37.5 & 16.7 & 22.7 & 17.5 & 29.8 \\
\hline Assurance & 6.5 & 2.7 & 3.5 & 6.2 & 6.6 & 6.3 & 6.8 & 9.1 & 7.1 & 5.8 \\
\hline Information & 3.2 & 3.5 & 3.5 & 13.7 & 13.2 & 13.6 & 25.0 & 27.3 & 25.3 & 15.8 \\
\hline
\end{tabular}

Consumers' selection of the single most important factor influencing their store patronage was consistent with the factor importance ratings (see Table 8).

Respondents who shopped primarily at the Home Depot were most likely to select assortment and pricing as the primary factor influencing their store choice. The largest share of patrons of the Do-It center selected accessibility as the primary factor, followed by assortment. ACE loyalists were more likely to select information as the primary factor influencing their store choice.

The importance ratings match up with customer perceptions of the retailers who perform best on each factor. Home Depot is perceived to have the best pricing and assortment, and respondents who shop there most often place considerable importance on these factors. The local incumbents' perceived strengths were in ambiance, accessibility, and information, and respondents who patronized these stores placed more importance on these factors than the Home Depot loyalists.

Binary logistic regression was used to determine how effectively the importance ratings could be used to predict store patronage. A binary choice variable was created and assigned a value of one if the respondent shopped most often at the Home Depot, and a value of zero otherwise. The importance ratings of prices and each of the distribution services were used as predictor variables. The resultant model had an $87.1 \%$ prediction accuracy, and the estimated coefficients and Wald statistics for each of the predictor variables serves as an indication of their significance in predicting big box versus smaller store patronage. Assortment was the primary predictor $(B=0.914$, Wald $=30.4)$, followed by pricing $\quad(B=0.441, \quad$ Wald $=14.3), \quad$ information $(B=-0.534$, Wald $=13.4)$, and location $(B=-0.242$, Wald =5.6). Assurance and ambiance were not significant predictors. The valence of the coefficients suggests that there is a positive association between Home Depot patronage and the importance of both pricing and assortment, but a negative association with the perceived importance of information and accessibility.

A final stage of analysis was used to identify consumers who place greater importance on distribution 
Table 9

Proportion of respondents who placed greater importance on variables other than price and assortment

\begin{tabular}{lclr}
\hline Distribution service & Wave I & Wave II & Total \\
\hline Assurance & 36.9 & 37.7 & 37.1 \\
Information & 32.0 & 34.0 & 32.6 \\
Accessibility & 28.7 & 27.4 & 28.4 \\
Ambiance & 7.6 & 10.2 & 8.3 \\
\hline
\end{tabular}

services that favor the smaller retailers. The percentage of respondents who rated the importance of accessibility, assurance, information, or ambiance higher than both price and assortment was calculated (see Table 9).

The data from both waves of the survey indicate that there is a segment of consumers who places greater importance on the provision of distribution services other than price and assortment, which favor the Home Depot. The distribution service most often rated as more important than price and assortment is assurance of product delivery in the desired form and at the desired time, followed by information, accessibility of location, and ambiance.

\subsection{Retailer performance results}

We also gathered data regarding the incumbents' market share and financial performance in order to compare their performance with their retail strategy. When the Home Depot opened, both incumbents experienced a drop in market share. The percentage of respondents who shopped most often at the Do-It center dropped from $64.3 \%$ to $43.4 \%$ and those patronizing the ACE store most often dropped from $15.5 \%$ to $7.9 \%$, while the percentage of respondents visiting the Home Depot most often increased from $3.6 \%$ to $40.5 \%$ (see Table 8).

Management from each of the incumbent retailers provided data regarding their financial performance before and after Home Depot opened. In order to maintain confidentiality, the retailers reported both sales and profitability data as indices. Sales and gross profits during a month just prior to the study were used as the baseline, and each retailer divided their monthly sales and profit data by the August baseline figures to generate an index. Only the index data are reported in the study. Both retailers experienced a drop in sales after Home Depot's opening (see Fig. 1). Despite a drop in sales, the ACE store was able to maintain consistent profitability even after the Home Depot's entry in the market, but the Do-It center experienced considerable losses (see Fig. 2).

These data indicate that the neighborhood ACE store fared much better than the regional Do-It center when Home Depot entered the market. Several elements of the retailers' strategies might account for this performance.

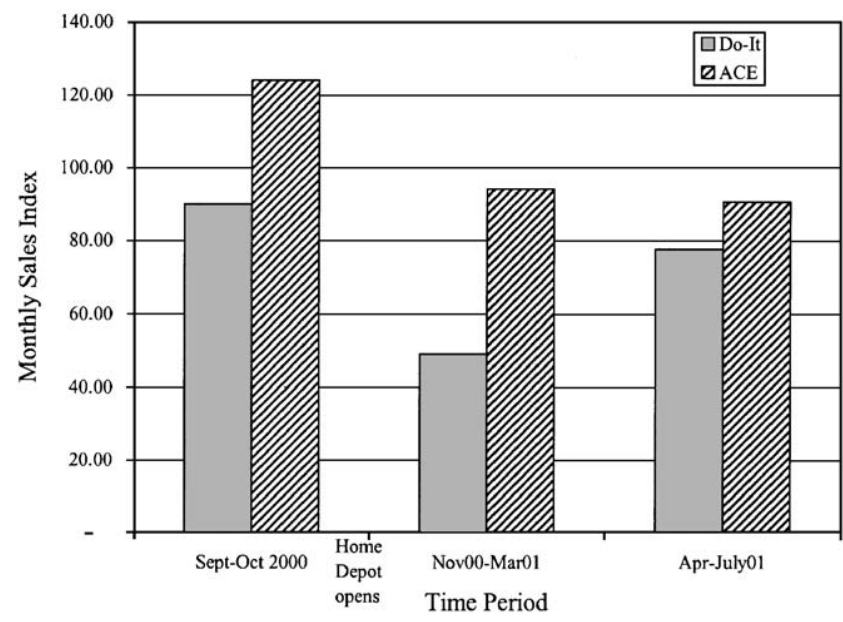

Fig. 1. Monthly sales index of incumbent retailers.

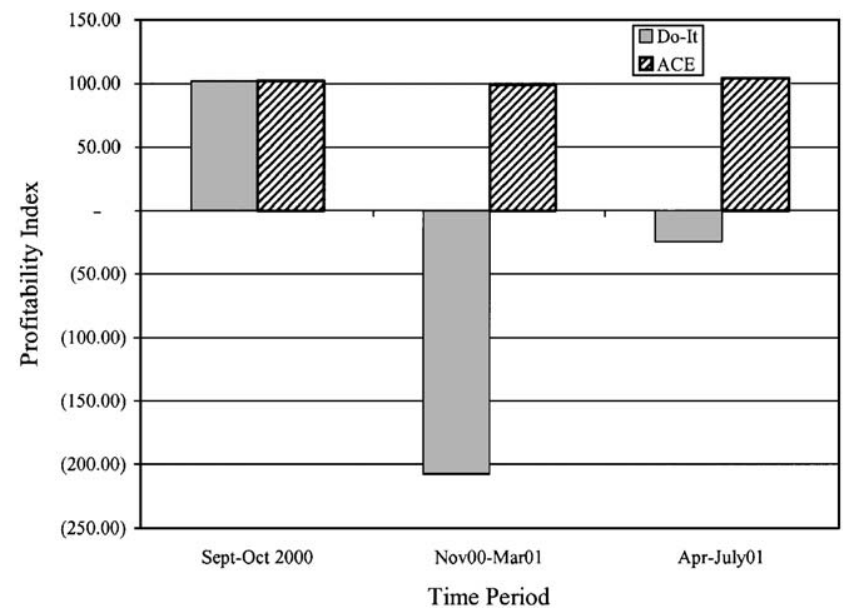

Fig. 2. Profitability index of incumbent retailers.

First, the ACE management informed us that they chose to raise prices of several items, allowing them to maintain gross profits with lower unit sales. This strategy can be justified on the basis that Home Depot "owns" pricing and assortment, so incumbent retailers should not attempt to match Home Depot on these performance variables. Second, the ACE store maintained high performance on factors that are particularly reliant on human resources - friendly and knowledgeable store personnel, prompt in-store assistance, and speedy transactions. These factors translate to higher levels of information, ambiance, and assurance of product delivery at the desired time than the Home Depot.

\subsection{General discussion}

The fundamentals of chain-store economics suggest that the Home Depot and other large-format "category killers" can achieve economies of scale enabling them to 
offer lower prices and a larger overall assortment than smaller retailers. The data in this study are consistent with this conjecture. The results also indicate that a sizable market segment places central importance on these factors, thus leading them to patronize the Home Depot. Smaller retailers who try to compete against the Home Depot on these factors are not likely to succeed. The results from this study also highlight a potential market niche for the local incumbent retailers who strive to achieve competitive positioning against Home Depot. Although not a majority of the market, there is a substantial share of consumers who place greater importance on certain distribution services that some local retailers can deliver more effectively than the Home Depot, thereby reducing consumers' distribution costs. These distribution services relate primarily to accessibility, as well as the human factor of retailing the management and store personnel who provide ambiance, assurance of product delivery, and information. In this market, the smaller neighborhood ACE store was able to maintain profitability after the Home Depot opened by maintaining and in some cases increasing consumer perceptions of their delivery of these services.

These results are complimentary to prior research by Litz and Stewart (1998, 2000a-d) that has examined several strategies small incumbent retailers might use to achieve competitive advantage including membership in trade name franchises, building and nurturing highly personalized customer relationships and community involvement, and offering "extraordinary accessibility" by making the store available for after-hour customer emergencies such as a broken water pipe. All of this research points to the fact that local incumbent retailers need to provide a distinctive combination of distribution services that consumers value and that the Home Depot cannot deliver at a high level.

This study also addresses the need to clearly define retailing and develop a comprehensive retailing theory (Peterson and Balasubramanian, 2002). The distribution services framework that is applied in this study defines the central economic function of retail firms and conceptualizes retail strategy as the delivery of distribution services that offset consumers' distribution costs. The usefulness of this approach is demonstrated in this study by revealing specific types of distribution services that offer a competitive niche for smaller retailers who seek to survive in the midst of big box dominance.

\subsection{Limitations}

The primary purpose of our study was to compare the level of distribution services delivered by a big box retailer relative to local incumbent retailers, in order to identify potential competitive niches for smaller competitors. Although our use of both mystery shopper and consumer survey data strengthens the reliability of our findings, the fact that the data were drawn from a single market limits their generalizability. In order to test whether smaller, local retailers have a systemic advantage in delivering higher levels of certain distribution services, data from a broad sample of regional markets would be necessary. This research establishes the measures that can be used for a more extensive study, and provides insights where smaller retailers may find their competitive niche.

\section{References}

Andersen, A.L.L.P., 1997. Small Store Survival: Success Strategies for Retailers. Wiley, New York.

Arnold, S.J., 2000. Market impacts of large format retailers. Journal of Retailing and Consumer Services 7, iii-iv.

Arnold, S.J., Luthra, M.N., 2000. Market entry effects of large format retailers: a stakeholder analysis. International Journal of Retail \& Distribution Management 28 (4/5), 139-154.

Arnold, S.J., Handelman, J., Tigert, D.J., 1998. The impact of a market spoiler on consumer preference structures (or, what happens when Wal-Mart comes to town). Journal of Retailing and Consumer Services 5 (1), 1-13

Bain, J.S., 1968. Industrial Organization. Wiley, New York.

Betancourt, R.R., Gautschi, D.A., 1986. The evolution of retailing: a suggested economic interpretation. International Journal of Research in Marketing 3, 217-232.

Betancourt, R.R., Gautschi, D.A., 1988. The economics of retail firms. Managerial and Decision Economics 9, 133-144.

Betancourt, R.R., Gautschi, D.A., 1990. Demand complementarities, household production, and retail assortments. Marketing Science 9 (2), 146-161.

Betancourt, R.R., Gautschi, D.A., 1993. Two essential characteristics of retail markets and their economic consequences. Journal of Economic Behavior and Organization 21, 277-294.

Bitner, M.J., 1992. Servicescapes: the impact of physical surroundings on customers and employees. Journal of Marketing 56, 57-71.

Brennan, D.P., Lundsten, L., 2000. Impacts of large discount stores on small U.S. towns: reasons for shopping and retailer strategies. International Journal of Retail \& Distribution Management 28 (4/5), 155-161.

Daft, R., Lengel, R., 1990. Information richness: a new approach to managerial behavior and organization design. In: Cummings, L., Staw, B. (Eds.), Information and Cognition in Organizations. JAI Press, Greenwich, CT.

Darrow, W.P., Smith, R.D., Fabricant, R.A., 1994. Home depot and the home center industry competitive strategy and mobility barriers. Mid-Atlantic Journal of Business 30 (3), 227-239.

Darrow, W.P., King, A.B., Helleloid, D., 2001. David vs. Goliath in the hardware industry: generic strategies and critical success factors as revealed by business practice. The Mid-Atlantic Journal of Business 37 (2/3), 97-109.

Eroglu, S.A., Machleit, K.A., 1990. An empirical study of retail crowding: antecedents and consequences. Journal of Retailing 66 (2), 201-221.

Finn, A., Kayande, U., 1999. Unmasking a phantom: a psychometric assessment of mystery shopping. Journal of Retailing 75 (2), 195-217.

Glazer, R., 1991. Marketing in an information-intensive environment: strategic implications of knowledge as an asset. Journal of Marketing 55 (4), 1-19. 
Ingene, C.A., 1984. Productivity and functional shifting in spatial retailing: private and social perspectives. Journal of Retailing 60 (3), 15-36.

Kotler, P.1974)., 1973. Atmospherics as a marketing tool. Journal of Retailing 49 (4), 48-64.

Litz, R.A., Stewart, A.C., 1998. Franchising for sustainable advantage? Comparing the performance of independent retailers and trade-name franchises. Journal of Business Venturing 13, 131-150.

Litz, R.A., Stewart, A.C., 2000a. Charity begins at home: family firms and patterns of community involvement. Nonprofit and Voluntary Sector Quarterly 29 (1), 131-148.

Litz, R.A., Stewart, A.C., 2000b. The late show: the effects of afterhours accessibility on the performance of small retailers. Journal of Small Business Management 38 (1), 1-26.

Litz, R.A., Stewart, A.C., 2000c. Research note: trade name franchise membership as a human resource management strategy: does buying group training deliver 'True Value' for small retailers? Entrepreneurship: Theory \& Practice 25 (1), 125-135.
Litz, R.A., Stewart, A.C., 2000d. Where everybody knows your name: extraorganizational clan-building as small firm strategy for home field advantage. Journal of Small Business Strategy 11 (1), 1-13.

Marcus, B., Blank, A., Andelman, B., 1999. Built from Scratch. Crown Business, New York.

Morganosky, M.A., Cude, B.J., 2000. Large format retailing in the U.S.: a consumer experience perspective. Journal of Retailing and Consumer Services 7, 215-222.

Peterson, R.A., Balasubramanian, S., 2002. Retailing in the 21st century: reflections and prologue to research. Journal of Retailing 78 (1), 9-16.

Peterson, M., McGee, J.E., 2000. Survivors of "W-day": an assessment of the impact of Wal-Mart's invasion of small town retailing communities. International Journal of Retail \& Distribution Management 28 (4/5), 170-180.

Porter, M.E., 1980. Competitive Strategy. The Free Press, New York.

Wu, B.T.W., Petroshius, S.M., 1987. The halo effect in store image management. Journal of the Academy of Marketing Science 15 (3), $44-51$. 